\title{
Construction of Collagen Scaffolds That Mimic the Three-Dimensional Architecture of Specific Tissues
}

\author{
KAEUIS A. FARAJ, Ph.D., ${ }^{1,2}$ TOIN H. VAN KUPPEVELT, Ph.D., \\ and WILLEKE F. DAAMEN, Ph.D. ${ }^{1}$
}

\begin{abstract}
Every tissue and organ has its own 3-dimensional (3D) extracellular matrix (ECM) organization. Cells in a 3D bioscaffold for tissue engineering typically align new ECM components according to the bioscaffold provided. Therefore, scaffolds with a specific 3D structural design resembling the actual ECM of a particular tissue may have great potential in tissue engineering. Here, we show that, using specific freezing regimes, 3D scaffolds that mimic the 3D architecture of specific tissues can be made from collagen. Three examples are given, namely, scaffolds resembling the cup-shaped parenchymal (alveolar) architecture of lung, scaffolds that mimic the parallel collagen organization of tendon, and scaffolds that mimic the 3D organization of skin. For the preparation of these tissue-specific scaffolds, we relied on simple techniques without the need for expensive or customized equipment. Freezing rate, type of suspension medium, and additives (e.g., ethanol) were found to be prime parameters in controlling scaffold morphology.
\end{abstract}

\section{INTRODUCTION}

$\mathbf{T}$ HE ORGanization OF THE EXTRACEllular Matrix (ECM), which comprises many different molecules, including proteins and proteoglycans, principally provides the basic architecture of a tissue. The body uses one group of proteins, the collagens and in particular type I collagen, as the main scaffold material. Collagens are the most ubiquitous and abundant components in mammals and provide strength and structural integrity to all organs, including skin, tendon, and bone.

Type I collagen has been used as a biomaterial in a variety of applications because of a number of useful properties, including low antigenicity and appropriate mechanical characteristics. Concerns such as mechanical properties and biochemical characteristics are usually well addressed in the field of (collagen) scaffolding. ${ }^{1-5}$ However, one concern is frequently overlooked: the 3-dimensional (3D) structural design. The orientation of collagen fibers and fibrils is of crucial importance for the functioning of organs and tissues and plays a decisive role in their biomechanical properties. ${ }^{6}$ For instance, in tendon collagen, fibrils are ordered in a highly parallel alignment, thus providing great tensile strength. In skin, the collagen fibrils are oriented in a wavy, meandering way, thus allowing the skin to stretch but preventing overstretching. In the lung, collagen fibrils form a delicate, cuplike matrix, giving lung alveoli their shape and sustaining the process of gas exchange.

We have previously shown that cells in a 3D bioscaffold typically synthesize their new ECM molecules following the presented scaffold (Fig. 1). ${ }^{7,8}$ Also, scaffold heterogeneity can affect the ability of the cells to produce a uniform ECM distribution. ${ }^{9}$ The methodologies currently available to shape scaffolds prepared from natural proteins, including collagen, are limited. A number of techniques, such as heating and the use of harsh chemicals, frequently applied in the construction of scaffolds from synthetic polymers, are not applicable to proteins because they would denature them and

\footnotetext{
${ }^{1}$ Department of Biochemistry, Nijmegen Centre for Molecular Life Sciences, Radboud University Nijmegen Medical Center, Nijmegen, The Netherlands.

${ }^{2}$ EMCM BV, Nijmegen, The Netherlands.
} 


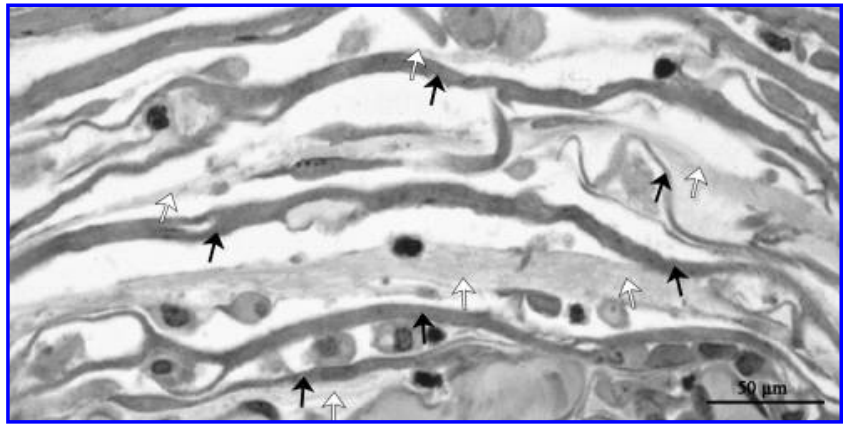

FIG. 1. Alignment of newly formed extracellular matrix components. Newly formed collagen fibers generally align in the same direction as the provided collagen scaffold. In the example given here, a collagen scaffold was subcutaneously implanted in an adult Wistar rat and retrieved after 28 days; methacrylate sections were toluidine blue stained. ${ }^{7}$ Black arrows indicate the provided collagen scaffold; white arrows indicate newly formed collagen fibers.

destroy their biological properties. ${ }^{10,11}$ Milder techniques are required. The objective of this study is to influence the structural design of collagen scaffolds prepared using lyophilization techniques to obtain scaffolds resembling the 3D organization of the ECM in vivo. Experimental variables are freezing temperature, type of suspension medium, and additives (e.g., ethanol). Focus tissues are lung, tendon, and skin.

\section{MATERIALS AND METHODS}

\section{Analysis of the ECM architecture in situ}

The ECM of a 50-mg bovine tendon piece was extracted at $22^{\circ} \mathrm{C}$ using 3 extractions with $2 \mathrm{~mL}$ of 2.5 -M sodium hydroxide for $2 \mathrm{~h}$ each, followed by 3 washings with demineralized water, 1 extraction with $2 \mathrm{~mL}$ of $1 \%$ aqueous tannic acid for $3 \mathrm{~h}$, and 6 washings with demineralized water, for $16 \mathrm{~h}$ in total. ${ }^{12,13}$ The preparations were fixed in $1 \%(\mathrm{w} / \mathrm{v})$ osmium tetroxide in demineralized water for $3 \mathrm{~h}$, dehydrated in an ascending series of acetone in water solutions, critical point dried in a Polaron E3000 apparatus (Quorum Technologies, Newhaven, UK) using liquid carbon dioxide $\left(\mathrm{CO}_{2}\right)$, and studied using scanning electron microscopy (SEM). For human lung and human skin, data were taken from literature. ${ }^{14-16}$

\section{Preparation of insoluble type I collagen}

Bovine Achilles tendons were defatted, freed from adhering non-collagenous material, and frozen in liquid nitrogen $\left(-196^{\circ} \mathrm{C}\right)$. The frozen tendon pieces were pulverized using a universal cutting mill (Pulverisette 19, Fritsch GmbH, IdarOberstein, Germany) and sieved through a $0.5-\mathrm{mm}$ sieve with continuous cooling using liquid nitrogen. Insoluble type I collagen (containing its telopeptides) was isolated from the pulverized material using salt solutions $(0.1-\mathrm{M}$ and $1.0-\mathrm{M}$ sodium chloride in demineralized water), diluted acetic acid with and without 4-M urea, and acetone, as previously described. ${ }^{17}$ All solutions were prepared using ultrapure water from a Biocel A10 grade MilliQ system (Millipore, Billerica, MA). Finally, the purified collagen was lyophilized in a Sublimator 500 II freeze dryer (Zirbus Technology, Bad Grund, Germany).

\section{Preparation of collagen scaffolds}

A collagen suspension was prepared by incubation of $0.9 \%$ purified insoluble type I collagen in $0.25-\mathrm{M}$ acetic acid (pH 2.75) at $4^{\circ} \mathrm{C}$ for $16 \mathrm{~h}^{3,18}$ The suspension was homogenized on ice using a Teflon glass Potter-Elvehjem homogenizer (Louwers Glass and Ceramic Technologies, Hapert, The Netherlands) with an intervening space of $0.35 \mathrm{~mm}$, and entrapped air bubbles were removed using centrifugation at $525 \mathrm{~g}$ for $5 \mathrm{~min}$ at $4^{\circ} \mathrm{C}$. Finally, $4 \mathrm{~mL}$ of the collagen suspension was poured into 1 well of a 6 -well suspension culture plate (Greiner Cellstar, Frickenhausen, Germany), frozen, and lyophilized. For all parameters, 3 individual scaffolds were analyzed. The final diameter of the scaffold was $35 \mathrm{~mm}$, with $4 \mathrm{~mm}$ thickness.

\section{Influence of freezing temperature and solute}

To study how the freezing temperature influences scaffold formation, the collagen suspension was frozen at different temperatures: $-20^{\circ} \mathrm{C}\left(-20^{\circ} \mathrm{C}\right.$ freezer), $-80^{\circ} \mathrm{C}$ (a mixture of dry $\mathrm{CO}_{2}$ ice and ethanol), and $-196^{\circ} \mathrm{C}$ (liquid nitrogen). To calculate average pore sizes, the pore size was measured manually from SEM images in 2 directions perpendicular to each other. Per scaffold site, the mean pore size of 100 pores of 3 individually prepared scaffolds was determined.

To study how diluted acetic acid influences scaffold formation, the collagen suspension was prepared in $0.25-\mathrm{M}$ acetic acid and in pure water and frozen at $-20^{\circ} \mathrm{C}\left(-20^{\circ} \mathrm{C}\right.$ freezer). Ethanol lowers the freezing point of the suspension medium and therefore influences scaffold structure. The effect of ethanol addition was studied by preparing a collagen suspension in water or $0.25-\mathrm{M}$ acetic acid with and without $2.8 \%(\mathrm{wt} / \mathrm{wt}$ ) ethanol, homogenizing, de-aerating, and freezing at $-80^{\circ} \mathrm{C}$ using a mixture of dry $\mathrm{CO}_{2}$ ice and ethanol and lyophilizing.

\section{Preparation of lung scaffold}

The principal function of the lung is to exchange gases between the blood and air, a process that is mainly carried out at the alveoli. The architecture of the alveoli comprises thin alveolar walls that enclose rounded air-filled pores. ${ }^{19} \mathrm{~A}$ scaffold resembling the alveolar structures of the lung should therefore contain rounded pores separated by thin walls. To prepare a scaffold mimicking the ECM morphology of lung, the collagen suspension in $0.25-\mathrm{M}$ acetic acid was slowly frozen in a $-20^{\circ} \mathrm{C}$ freezer before lyophilization. 


\section{Preparation of tendon scaffold}

Tendon connects muscle to bone and consists of longitudinally oriented collagen fibers, aligned in a parallel mode, of several $\mathrm{cm}$ in length containing specialized fibroblasts. ${ }^{20}$ To prepare a scaffold resembling the ECM structure in tendons, liquid propane, a faster freezing agent than liquid nitrogen, was used. The collagen suspension in $0.25-\mathrm{M}$ acetic acid was extruded through a 21-gauge syringe directly into liquid nitrogen-cooled propane, left to solidify, and lyophilized.

\section{Preparation of skin scaffold}

The skin is basically composed of 2 layers: the epidermis (containing the keratinocytes), resting on a thin, dense matrix (the basement membrane), and the dermis, which is largely made up of ECM components, notably type I collagen in a wavy, meandering organization. ${ }^{19}$ To obtain a matrix resembling the skin, including a dense, closed surface, a collagen suspension in water containing $2.8 \%$ (wt/wt) ethanol was frozen at $-80^{\circ} \mathrm{C}$ (in a mixture of dry $\mathrm{CO}_{2}$ ice and ethanol).

\section{Analysis of isolated collagen fibrils}

Transmission electron microscopy. Collagen fibrils were swollen in $0.25-\mathrm{M}$ acetic acid for $16 \mathrm{~h}$ at $4^{\circ} \mathrm{C}$, placed on a formvar-coated grid for $30 \mathrm{~min}$, and washed with $0.1-\mathrm{M}$ phosphate buffer ( $\mathrm{pH}$ 7.4). The air-dried specimen was stained with lead citrate and uranyl acetate and examined in a JEOL 1010 electron microscope (JEOL, Tokyo, Japan).

Scanning electron microscopy. Collagen fibrils were studied with a Philips XL30 ESEM FEG apparatus (Philips, Eindhoven, The Netherlands) at an accelerating voltage of $10 \mathrm{kV}$.

\section{Analysis of collagen scaffolds}

Specimen preparation. To explore the architectural structure of the scaffolds, different sites were examined, representing the top, the pan side, and the cross-section. The top is the surface in contact with air during freezing (collagen suspension/air interface). The pan side is the bottom, where the cast is in contact with the cooling medium. The crosssection is taken perpendicular to the top of the scaffold.

Scanning electron microscopy. Lyophilized collagen scaffolds were mounted on stubs and sputtered with an ultrathin layer of gold in a Polaron E5100 Coating System (Quorum Technologies). Collagen scaffolds were studied with a JEOL JSM-6310 SEM at an accelerating voltage of $15 \mathrm{kV}$.

\section{RESULTS}

\section{Collagen fibrils}

The purification procedure of the collagen fibrils did not influence their native constitution, as indicated by SEM and

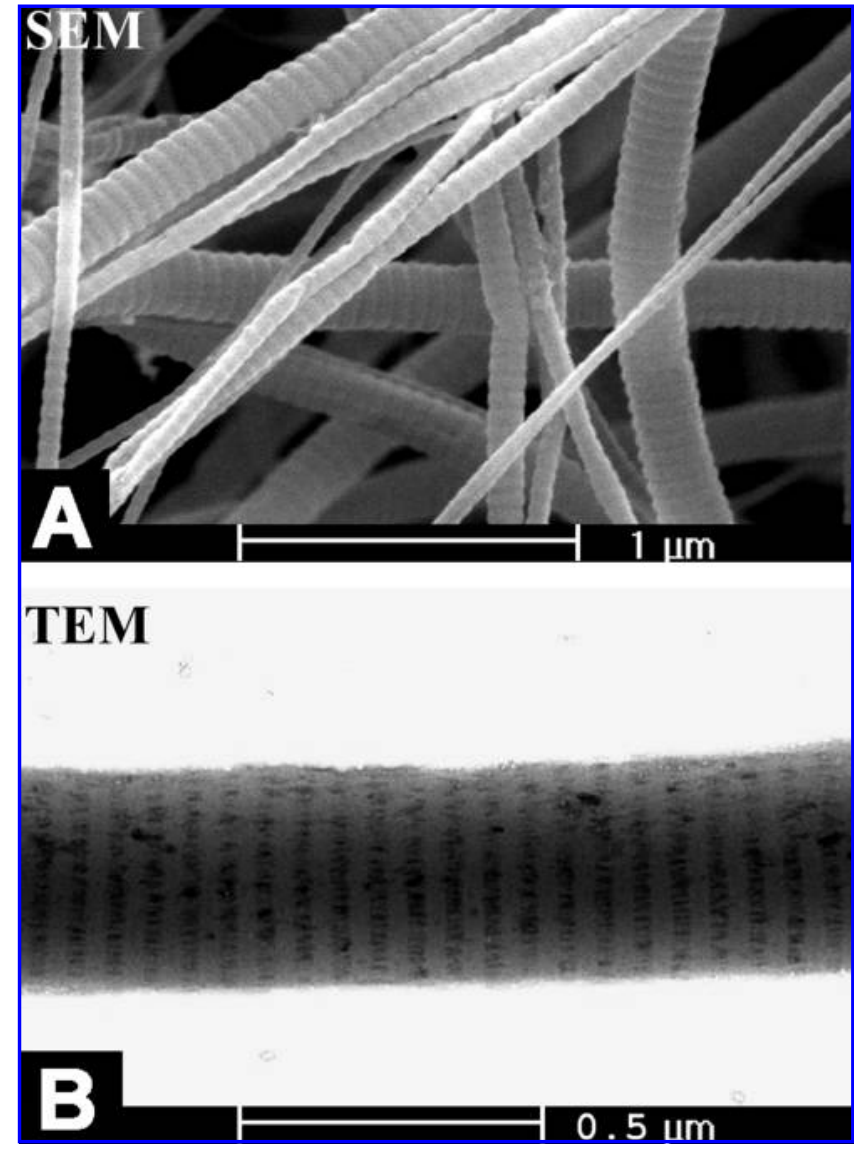

FIG. 2. Conformation of isolated collagen fibrils. Scanning (A) and transmission electron microscopy (B) reveal that the isolated collagen fibrils retained their original striated pattern. Bar is $1 \mu \mathrm{m}$ in $\mathbf{A}$ and $0.5 \mu \mathrm{m}$ in $\mathbf{B}$.

TEM analysis of individual collagen fibrils (Fig. 2). All collagen fibrils displayed the characteristic banding pattern.

\section{Collagen scaffolds}

Influence of freezing temperature and solute. When an acidic collagen suspension is frozen, ice crystals are formed that are removed during lyophilization, resulting in porous scaffolds. Because the pore structure after drying is a replica of the ice crystal morphology after freezing, the freezing regime is a way to influence scaffold morphology, as was explored here using SEM examination. The freezing conditions greatly influence the pore size, as shown in Table 1. It takes 40 to $45 \mathrm{~min}, 12$ to $15 \mathrm{~min}$, and 45 to $90 \mathrm{~s}$ to freeze the collagen suspension completely at $-20^{\circ} \mathrm{C},-80^{\circ} \mathrm{C}$, and $-196^{\circ} \mathrm{C}$, respectively. The use of a slow freezing process in $\mathrm{a}-20^{\circ} \mathrm{C}$ freezer resulted in larger pore sizes $(\sim 89 \mu \mathrm{m}$ in cross-section) than fast freezing using a mixture of dry ice and ethanol $\left(-80^{\circ} \mathrm{C} ; \sim 42 \mu \mathrm{m}\right.$ in cross-section), and the most rapid freezing procedure, using liquid nitrogen, lead to the smallest pores $\left(-196^{\circ} \mathrm{C} ; \sim 24 \mu \mathrm{m}\right.$ in cross-section). At $-20^{\circ} \mathrm{C}$, rounded pores were found throughout the scaffold: at the top and pan side as well as the cross-section (Fig. 3A, 
Table 1. Pore Sizes of Air Side, Pan Side and Cross Section in Scaffolds Frozen at Three Temperatures

\begin{tabular}{|c|c|c|c|}
\hline Scaffold section: & $\begin{array}{l}\text { Freezing at: } \\
\quad-20^{\circ} \mathrm{C}\end{array}$ & $-80^{\circ} \mathrm{C}$ & $-196^{\circ} \mathrm{C}$ \\
\hline Top side & $100 \pm 8 \mu \mathrm{m}$ & $57 \pm 21 \mu \mathrm{m}$ & $31 \pm 2 \mu \mathrm{m}$ \\
\hline Pan side* & $123 \pm 21 \mu \mathrm{m}$ & $29 \pm 3 \mu \mathrm{m}$ & $5 \pm 1 \mu \mathrm{m}$ \\
\hline Cross section & $89 \pm 24 \mu \mathrm{m}$ & $42 \pm 6 \mu \mathrm{m}$ & $24 \pm 4 \mu \mathrm{m}$ \\
\hline
\end{tabular}

*The pores at the pan side are difficult to assign, because they contain many collagen struts present within the pores, especially at $-196^{\circ} \mathrm{C}$ and $-80^{\circ} \mathrm{C}$.

Values are mean \pm SD of three individually prepared scaffolds, 100 pores were measured per site.

$D, G)$. The pore size of the pan side is larger than the pore size of the top, probably because of the insulating properties of the polystyrene holder used. At $-80^{\circ} \mathrm{C}$, cross-section images of scaffolds showed a regular pore structure with parallel lamellae connected by thin collagen struts. Freezing in liquid nitrogen prevents the formation of large ice crystals and thus leads to the formation of a spongeous microstructure with distinct regions: the pan side with small round pores (Fig. 3F), the top with larger round pores (Fig. 3C), and the cross-section with plate-like structures connected to each other with fine fibril bridges (Fig. 3I). At $-196^{\circ} \mathrm{C}$, more separate collagen struts connecting the lamellae were found than at $-80^{\circ} \mathrm{C}$ (see inserts in Fig. 3H and 3I).

When keeping the freezing conditions the same, the morphology of a scaffold from a collagen suspension in water displayed more thin thread-like structures than a scaffold from a collagen suspension in diluted acetic acid. The walls of the pores and lamellae were more compact and smoother in the diluted acetic acid scaffold, especially in the top view (Fig. 4). The influence of the addition of ethanol will be described under the "Skin scaffold" section.

Lung scaffold. The structure of human adult lung clearly shows the thin alveolar walls surrounding the rounded air spaces, forming cup-shaped structures (Fig. 5A, B).

Collagen scaffolds produced using lyophilization after slow freezing in a $-20^{\circ} \mathrm{C}$ freezer revealed a homogenous porous structure in cross- and longitudinal sections, containing rounded pores of similar size as observed in humans (Fig. 5C, D). In all directions, homogeneous and interconnected rounded pores are present, closely resembling the ECM architecture of lung.

Tendon scaffold. The ECM of bovine tendon clearly shows the longitudinally oriented, closely packed collagen fibers and fibrils (Fig. 6A, B).

When a collagen suspension was dropped into propane cooled with liquid nitrogen, the suspension froze during falling. A rod-shaped tail was formed, composed of a bundle of parallel fibers. This alignment was visible throughout the whole structure (Fig. 6C, D). Similar structures were obtained when a collagen droplet was let down into liquid nitrogen but with less longitudinal orientation, thicker collagen bundles, and a wider distance between the fibers (Fig. 6E, F).

Skin scaffold. SEM micrographs of human dermis show the thick meandering collagen fibers (Fig. 7A). The boundary

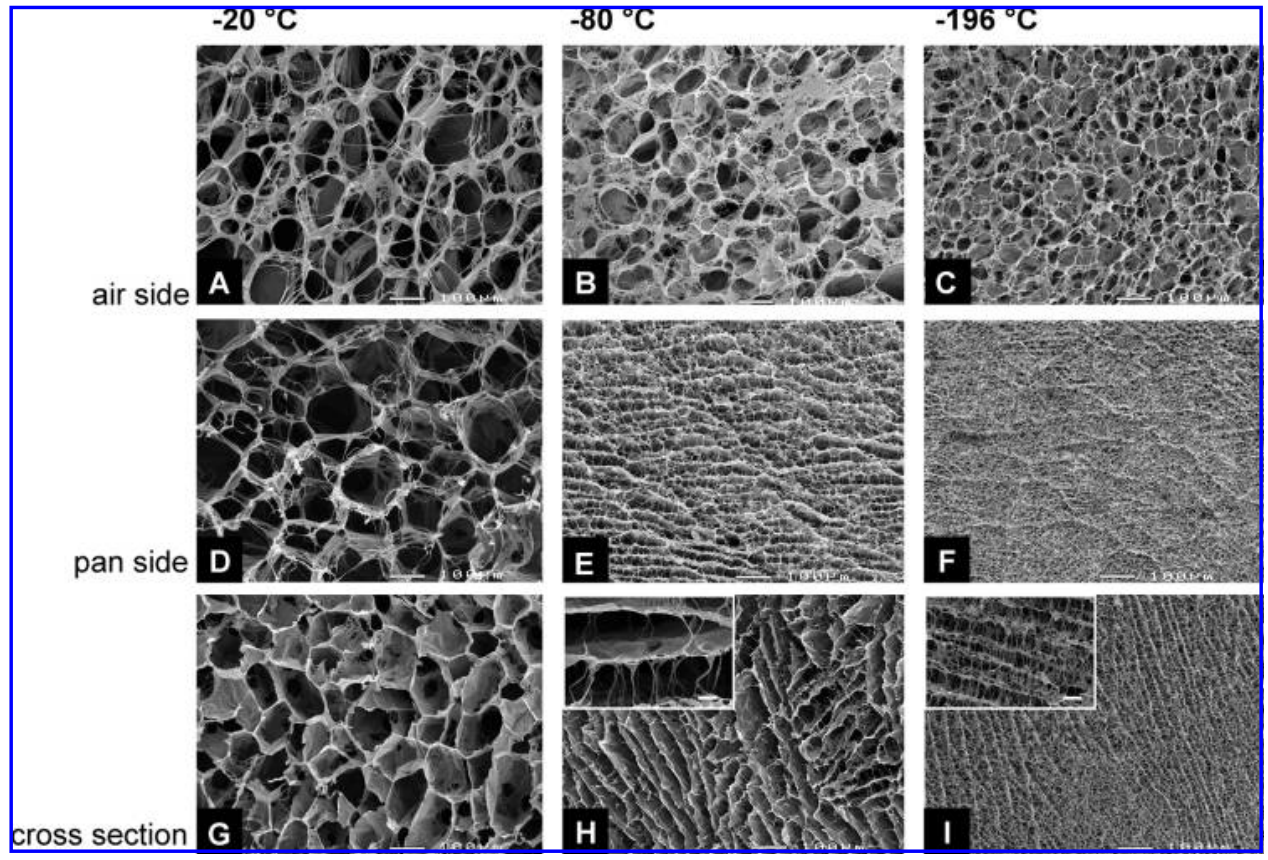

FIG. 3. Influence of freezing regime on scaffold morphology. Scanning electron micrographs of lyophilized collagen suspension in 0.25 -M acetic acid frozen at $-20^{\circ} \mathrm{C}(\mathbf{A}, \mathbf{D}, \mathbf{G}),-80^{\circ} \mathrm{C}(\mathbf{B}, \mathbf{E}, \mathbf{H})$, and $-196^{\circ} \mathrm{C}(\mathbf{C}, \mathbf{F}, \mathbf{I})$ showing top $(\mathbf{A}-\mathbf{C})$, pan side (D-F), and crosssection $(\mathbf{G}-\mathbf{I})$. Bars represent $100 \mu \mathrm{m}$, except for inserts in $\mathbf{H}$ and $\mathbf{I}(20 \mu \mathrm{m})$. 


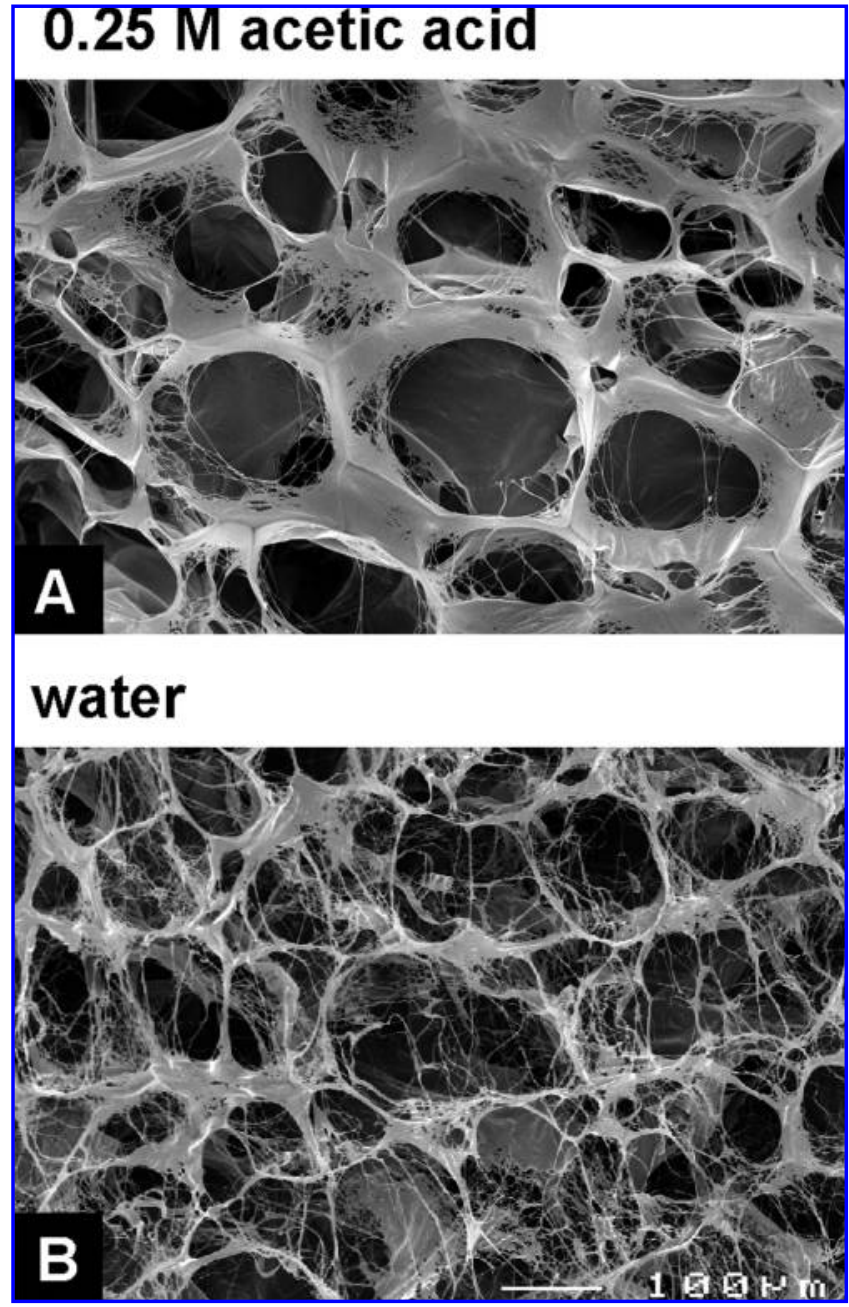

FIG. 4. Influence of diluted acetic acid on scaffold morphology. Scanning electron micrographs of the top of scaffolds prepared from a collagen suspension in $0.25-\mathrm{M}$ acetic acid (A) and water (B) frozen at $-20^{\circ} \mathrm{C}$. With water, more thread-like structures are found. Bar represents $100 \mu \mathrm{m}$.

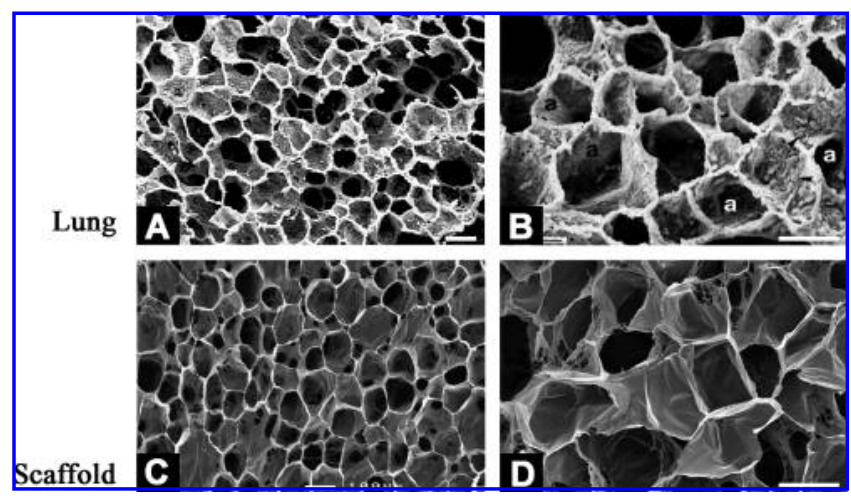

FIG. 5. SEM micrographs of the structure of human lung (A, B) and collagen scaffolds produced by freezing a collagen suspension in $0.25 \mathrm{M}$ acetic acid in $\mathrm{a}-20^{\circ} \mathrm{C}$ freezer followed by lyophilizing (cross sections) (C, D). Note the resemblance between human lung and the collagen scaffold. A reproduced from Wagner \& Hossler ${ }^{14}$; B from Zeltner \& Burri ${ }^{15}$. a: alveoli; bar is $100 \mu \mathrm{m}$.

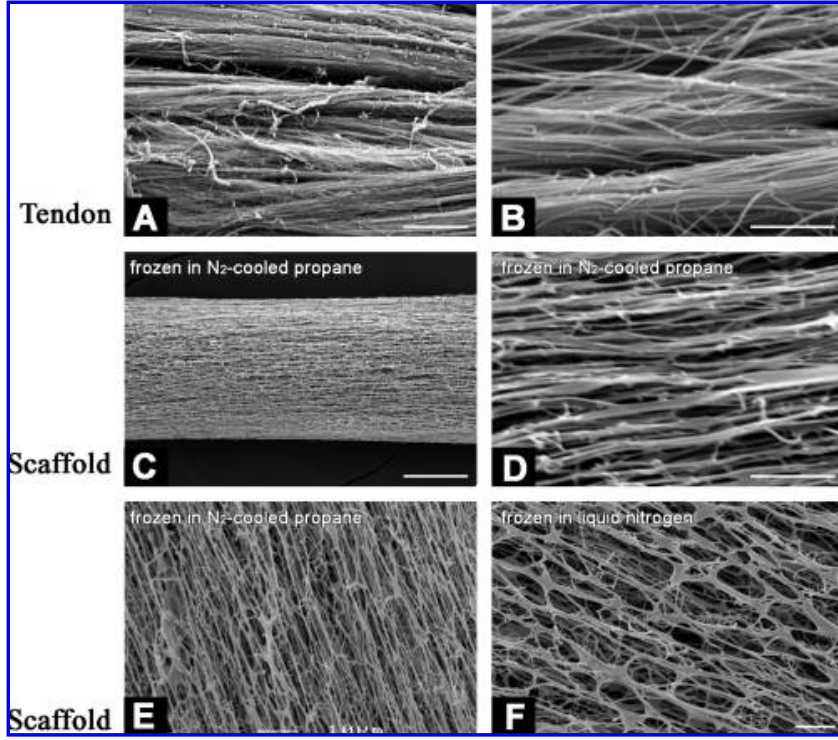

FIG. 6. Scanning electron micrographs of the extracellular matrix structure isolated from bovine tendon (A, B) and collagen scaffolds produced by dropping a collagen suspension in $0.25-\mathrm{M}$ acetic acid into liquid nitrogen-cooled propane $(\mathbf{C}-\mathbf{E})$ or liquid nitrogen $(\mathbf{F})$. Tendon and the collagen scaffold have similar aligned collagen fibrils. Bar is $50 \mu \mathrm{m}$ in $\mathbf{A}, \mathbf{C} ; 5 \mu \mathrm{m}$ in $\mathbf{B}, \mathbf{D}$, and $10 \mu \mathrm{m}$ in $\mathbf{E}, \mathbf{F}$.

between the epidermis and the dermis consists of a dense collagenous layer. Therefore, we aimed to prepare a collagen scaffold with a closed surface.

Addition of ethanol to a collagen suspension in water resulted in a dense, closed surface, whereas the underlying scaffold structure showed more lamellar structures than without ethanol addition, resembling the structure of the dermis

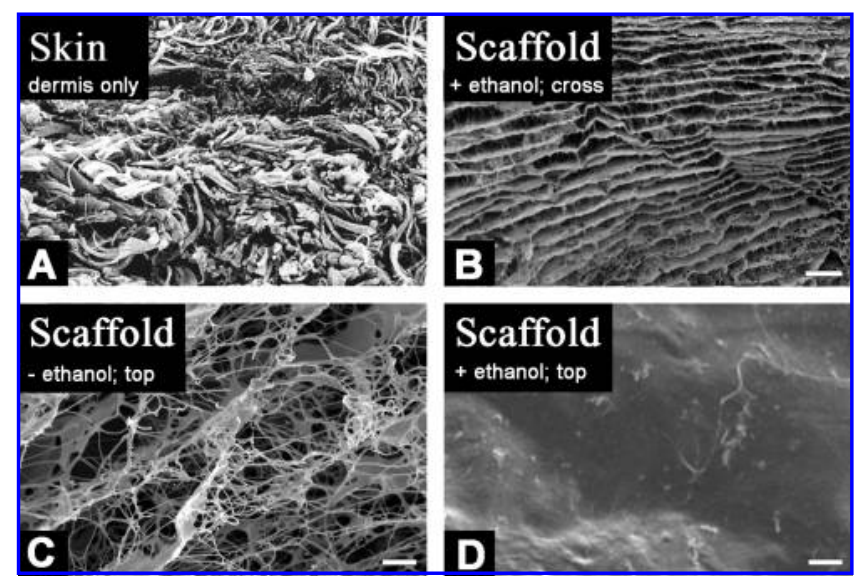

FIG. 7. Scanning electron micrographs of the structure of human adult dermis (A) and collagen scaffolds produced by freezing a collagen suspension in water in $\mathrm{a}-80^{\circ} \mathrm{C}$ bath followed by lyophilizing with (B, D) and without (C) $2.8 \%$ (wt/wt) ethanol in the collagen suspension. Addition of ethanol results in a porous scaffold with a dense air surface, resembling the epidermis and dermis structure. A reproduced from Royce and Steinman. ${ }^{16} \mathbf{B}$ shows the cross-section (100- $\mu \mathrm{m}$ bar); $\mathbf{C}$ and $\mathbf{D}$ are top views (10- $\mu \mathrm{m}$ bar). 
and epidermis. Similar results were obtained when a collagen suspension was prepared in $0.25-\mathrm{M}$ acetic acid containing $2.8 \%$ ethanol; the air surface collapsed, resulting in a dense surface with hardly any pores, but the porous inner structure of collagen scaffold was retained (results not shown).

\section{DISCUSSION}

When preparing scaffolds by freezing followed by lyophilization, the pore structure after drying is a replica of the ice crystal morphology after freezing. Therefore, the structure of the scaffold can be controlled directly using the employed freezing process and the heat transfer processes associated with it. ${ }^{9,21}$ Differences in heat transfer rates during the freezing process of the collagen suspension have a great effect on the microstructure of the fabricated scaffolds. If the cooling rate is fast enough to extract all the crystallization heat (e.g., liquid nitrogen-cooled propane), crystallization starts simultaneously in the entire collagen suspension, resulting in the formation of many small ice crystals and thus small pores. If the cooling rate is not rapid enough (e.g., when using a $-20^{\circ} \mathrm{C}$ freezer), ice crystal formation is slower, allowing the growth of larger ice crystals. ${ }^{22,23}$ Large interconnected pores were also seen when sodium alginate in water and poly $(\gamma-$ benzyl-L-glutamate) in pure dioxane (both rod-like polymers in solution) were frozen at a slow cooling rate (e.g., $-20^{\circ} \mathrm{C}$ ), as the result of random solvent crystallization. ${ }^{23,24}$ The surrounding medium has roughly the same temperature, and ice crystals will grow at the same rate in all directions, thus forming rounded pores. Freezing at a moderate cooling rate $\left(\right.$ e.g., $-80^{\circ} \mathrm{C}$ ) resulted in a sheet-like morphology showing a lamella structure connected by single, thin collagen struts. The temperature at the pan side is lower than at the top, resulting in directed (anisotropic) ice crystal growth (from the pan side to the top), hence forming lamellar structures. Freezing at a fast cooling rate (e.g., liquid nitrogen) results in an even more anisotropic ladder-like structure, in which the long axes of the ladders are parallel to the cooling direction, because the viscous collagen phase cannot be expelled fast enough as the ice crystals grow in size. This results in thinner ice crystals and consequently a smaller distance between lamellae. Freezing in liquid nitrogencooled propane is even faster, thus resulting in smaller distances between the collagen fibers (e.g., in tendon scaffolds, Fig. 6E, F). Quench freezing (fast freezing; e.g., -80 or $-196^{\circ} \mathrm{C}$ ) also results in multiple nucleation sites for ice crystal formation due to space- and time-variable heat transfer through the suspension, explaining the areas of oriented ice crystal growth (e.g., Fig. $3 \mathrm{H}, \mathrm{I}){ }^{9}$

In addition to freezing techniques, molding technology can be adopted to obtain the correct degree of anisotropy in the scaffolds. Collagen suspensions prepared as in this study are suitable to be shaped using a well-defined mold, thus providing the correct macroscopic and microscopic shape essential for tissue organization. In addition, industrial processes such as the BioAssembly Tool may be employed for this purpose. ${ }^{25}$

Scaffolds prepared from a collagen suspension in demineralized water demonstrated thin, randomly organized collagen fibrils in contrast to scaffolds prepared from a collagen suspension in aqueous acetic acid, which showed denser structures, probably because collagen swells under acidic conditions. Ethanol addition to a collagen suspension in water resulted in a fully closed surface with a porous scaffold underneath but without the characteristic thread-like structure as observed in water alone. Schoof et al. ${ }^{21}$ do not mention a non-porous surface with a suspension of collagen in aqueous ethanol.

Differences in 3D organization of a biomaterial, like pore size and porosity, have been shown to influence cellular behavior. Typical pore sizes are in the range of 100 to $200 \mu \mathrm{m}$, whereas typical porosities are in the range of $90 \%$ to $99 \% .{ }^{26}$ Published data on the pore sizes of lyophilized collagen scaffolds are consistent with our data. Differences that are found are likely to contribute to differences in freezing protocol and concentration of the materials. ${ }^{27}$ For example, O'Brien et al. found a larger mean cross-sectional pore size when a collagen suspension was frozen at $-20^{\circ} \mathrm{C}(121 \mu \mathrm{m}$ vs $89 \mu \mathrm{m})$ at a lower concentration. ${ }^{28}$

The mechanical properties of these scaffolds are weaker than of the original tissue. The tensile strength of tendon is approximately 50 to $100 \mathrm{Mpa} ;{ }^{29,30}$ of skin, approximately $20 \mathrm{Mpa} ;{ }^{31}$ and of lung, only 1 to $2 \mathrm{Mpa}^{32,33}$ The tensile strength of a non-cross-linked scaffold frozen at $-80^{\circ} \mathrm{C}$ is approximately $100 \mathrm{kPa}$ but can be improved to approximately $700 \mathrm{kPa}$ using chemical cross-linking using 1-ethyl3-(3-dimethyl aminopropyl) carbodiimide/N-hydroxysucc inimide, ${ }^{3,17}$ whereas mechanical properties of collagen gels are inferior to these scaffolds (i.e., $5 \mathrm{kPa}$ ). ${ }^{34}$ Chemical crosslinking also decreased the susceptibility of the scaffolds to enzymatic digestion in vitro and reduced the in vivo degradation rate after subcutaneous implantation in adult Wistar rats (non-crosslinked scaffolds 2-3 weeks, crosslinked scaffolds 10-12 weeks). ${ }^{8,17}$ When cells add new ECM to the scaffold after implantation, mechanical properties will most likely improve because of the correct alignment of these collagen fibers, resulting in values similar to those of native tissue. For example, increased fibrillar alignment led to increased interactions between fibrils and thus improved tensile strength. ${ }^{35}$

The 3D architecture of the scaffold is of great importance for the behavior of cells. Cells behave differently in a 3D environment than in a 2-dimensional structure. ${ }^{36-39}$ In lung, the main characteristics are the thin alveolar walls encompassing cup-shaped pores, similar to our lung scaffold. Chen et $a .^{40}$ recently showed that fetal rat lung cells grown in a collagen-glycosaminoglycan scaffold were capable of forming and maintaining alveolar-like structures. A scaffold that already resembles the alveolar structure of the lung may improve this kind of culturing experiments. In tendon, 
alignment of the collagen bundles is the most important characteristic. Fibroblasts align to synthesize an aligned ECM. ${ }^{41}$ Fibroblasts grown in the tendon scaffold will also align and produce new ECM in the same direction. In skin, a closed surface permits water retention to reduce dehydration and infection and allows the overgrowth of keratinocytes. We have previously seen that keratinocytes cultured on porous scaffolds tend to infiltrate these scaffolds, instead of being present as flat layers at the top. Our skin scaffold contains thinner collagen fibers and is more porous than the adult situation, but this gives fibroblasts the space to remodel the scaffold and synthesize thicker collagen bundles.

For the preparation of these tissue-specific scaffolds, we rely on simple techniques without the need for expensive and customized equipment, hence allowing a methodology that can be used in every laboratory. Previously, we have shown that it is possible to influence several biochemical and biomechanical parameters of molecularly defined scaffolds composed of collagen, elastin, glycosaminoglycans (including heparin, heparan sulfate, chondroitin sulfate, and dermatan sulfate), and growth factors (e.g., fibroblast growth factor 2 and vascular endothelial growth factor). ${ }^{3,17,42}$ The preparation of biochemically and morphologically defined scaffolds may contribute to a rational design of scaffolds for tissue engineering.

\section{ACKNOWLEDGMENTS}

The authors thank Dr. Björn Atthoff and Prof.dr Jöns Hilborn (Department of Materials Chemistry, Angström Laboratory, Uppsala, Sweden) for the ESEM analysis. This study was financially supported by the Dutch Program for Tissue Engineering (grant no. DPTE6735).

\section{REFERENCES}

1. Buttafoco, L., Engbers-Buijtenhuijs, P., Poot, A.A., Dijkstra, P.J., Daamen, W.F., Van Kuppevelt, T.H., Vermes, I., and Feijen, J. First steps towards tissue engineering of smalldiameter blood vessels: preparation of flat scaffolds of collagen and elastin by means of freeze drying. J. Biomed. Mater. Res. B Appl. Biomater. 77, 357, 2005.

2. Cummings, C.L., Gawlitta, D., Nerem, R.M., and Stegemann, J.P. Properties of engineered vascular constructs made from collagen, fibrin, and collagen-fibrin mixtures. Biomaterials 25, 3699, 2004.

3. Daamen, W.F., Van Moerkerk, H.Th.B., Hafmans, T., Buttafoco, L., Poot, A.A., Veerkamp, J.H., and Van Kuppevelt, T.H. Preparation and evaluation of molecularly-defined collagenelastin-glycosaminoglycan scaffolds for tissue engineering. Biomaterials 24, 4001, 2003.

4. Van Der Kraan, P.M., Buma, P., van Kuppevelt, T., and Van Den Berg, W.B. Interaction of chondrocytes, extracellular matrix and growth factors: relevance for articular cartilage tissue engineering. Osteoarthritis. Cartilage. 10, 631, 2002.
5. Tabata, Y. Tissue regeneration based on growth factor release. Tissue Eng. 9 Suppl 1, S5, 2003.

6. Ingber, D.E., Mow, V.C., Butler, D., Niklason, L., Huard, J., Mao, J., Yannas, I., Kaplan, D., and Vunjak-Novakovic, G. Tissue engineering and developmental biology: going biomimetic. Tissue Eng. 12, 3265, 2006.

7. Daamen, W.F., Nillesen, S.T., Hafmans, T., Veerkamp, J.H., Van Luyn, M.J., and Van Kuppevelt, T.H. Tissue response of defined collagen-elastin scaffolds in young and adult rats with special attention to calcification. Biomaterials 26, 81, 2005.

8. Pieper, J.S., Van Wachem, P.B., Van Luyn, M.J., Brouwer, L.A., Hafmans, T., Veerkamp, J.H., and Van Kuppevelt, T.H. Attachment of glycosaminoglycans to collagenous matrices modulates the tissue response in rats. Biomaterials 21, 1689, 2000.

9. O’Brien, F.J., Harley, B.A., Yannas, I.V., and Gibson, L. Influence of freezing rate on pore structure in freeze-dried collagenGAG scaffolds. Biomaterials 25, 1077, 2004.

10. Hutmacher, D.W. Scaffold design and fabrication technologies for engineering tissues-state of the art and future perspectives. J. Biomater. Sci. Polym. Ed. 12, 107, 2001.

11. Hollister, S.J. Porous scaffold design for tissue engineering. Nat. Mater. 4, 518, 2005.

12. O'Donnell, M.D. and McGeeney, K.F. An alkali digestion method to expose connective tissue fibers: a scanning electron microscopy study of rat lung. J. Electron Microsc. Tech. 19, 486, 1991.

13. Ohtani, O., Ushiki, T., Taguchi, T., and Kikuta, A. Collagen fibrillar networks as skeletal frameworks: a demonstration by cell-maceration/scanning electron microscope method. Arch. Histol. Cytol. 51, 249, 1988.

14. Wagner, R.C. and Hossler, F.E. Mammalian Histology B408, Respiratory System Ultrastructure. Available at http://www .udel.edu/Biology/Wags/histopage/empage/er/er.htm, 2000 (accessed Sept. 11, 2006).

15. Zeltner, T.B. and Burri, P.H. The postnatal development and growth of the human lung. II. Morphology. Respir. Physiol. 67, 269, 1987.

16. Royce, P.M. and Steinman, B. Connective tissue and its heritable disorders-molecular, genetic and medical aspects. New York: Wiley-Liss, 2002.

17. Pieper, J.S., Oosterhof, A., Dijkstra, P.J., Veerkamp, J.H., and Van Kuppevelt, T.H. Preparation and characterization of porous crosslinked collagenous matrices containing bioavailable chondroitin sulphate. Biomaterials 20, 847, 1999.

18. Pieper, J.S., Hafmans, T., Veerkamp, J.H., and Van Kuppevelt, T.H. Development of tailor-made collagen-glycosaminoglycan matrices: EDC/NHS crosslinking, and ultrastructural aspects. Biomaterials 21, 581, 2000.

19. Junqueira, L.C., Carneiro, J., and Kelley, R.O. Functionele histologie. Reed Business Information, 2004.

20. Zhang, G., Young, B.B., Ezura, Y., Favata, M., Soslowsky, L.J., Chakravarti, S., and Birk, D.E. Development of tendon structure and function: regulation of collagen fibrillogenesis. J Musculoskelet. Neuronal. Interact. 5, 5, 2005.

21. Schoof, H., Apel, J., Heschel, I., and Rau, G. Control of pore structure and size in freeze-dried collagen sponges. J. Biomed. Mater Res. 58, 352, 2001.

22. Shapiro, L. and Cohen, S. Novel alginate sponges for cell culture and transplantation. Biomaterials 18, 583, 1997. 
23. Zmora, S., Glicklis, R., and Cohen, S. Tailoring the pore architecture in 3-D alginate scaffolds by controlling the freezing regime during fabrication. Biomaterials 23, 4087, 2002.

24. Jackson, C.L. and Shaw, M.T. The phase behaviour and gelation of a rod-like polymer in solution and implications for microcellular foam morphology. Polymer 31, 1070, 1990.

25. Smith, C.M., Stone, A.L., Parkhill, R.L., Stewart, R.L., Simpkins, M.W., Kachurin, A.M., Warren, W.L., and Williams, S.K. Three-dimensional bioassembly tool for generating viable tissueengineered constructs. Tissue Eng. 10, 1566, 2004.

26. Freyman, T.M., Yannas, I.V., and Gibson, L.J. Cellular materials as porous scaffolds for tissue engineering. Prog. Mater. Sci. 46, 273, 2001.

27. Boyce, S.T. and Hansbrough, J.F. Biologic attachment, growth, and differentiation of cultured human epidermal keratinocytes on a graftable collagen and chondroitin-6-sulfate substrate. Surgery 103, 421, 1988.

28. O'Brien, F.J., Harley, B.A., Yannas, I.V., and Gibson, L.J. The effect of pore size on cell adhesion in collagen-GAG scaffolds. Biomaterials 26, 433, 2005.

29. Wang, J.H. Mechanobiology of tendon. J. Biomech. 39, 1563, 2006.

30. Wren, T.A., Yerby, S.A., Beaupre, G.S., and Carter, D.R. Mechanical properties of the human achilles tendon. Clin. Biomech. (Bristol, Avon) 16, 245, 2001.

31. Jussila, J., Leppaniemi, A., Paronen, M., and Kulomaki, E. Ballistic skin stimulant. Forensic Sci. Int. 150, 63, 2005.

32. Pierce, J.A. Tensile strength of human lung. J. Lab. Clin. Med. 66, 652, 1965.

33. Senior, R.M., Bielefeld, D.R., and Abensohn, M.K. The effects of proteolytic enzymes on the tensile strength of human lung. Am. Rev. Respir. Dis. 111, 184, 1975.

34. Gildner, C.D., Lerner, A.L., and Hocking, D.C. Fibronectin matrix polymerization increases tensile strength of model tissue. Am. J. Physiol. Heart Circ. Physiol. 287, H46, 2004.

35. Pins, G.D., Christiansen, D.L., Patel, R., and Silver, F.H. Selfassembly of collagen fibers. Influence of fibrillar alignment and decorin on mechanical properties. Biophys. J. 73, 2164, 1997.
36. Inanc, B., Elcin, A.E., and Elcin, Y.M. Osteogenic induction of human periodontal ligament fibroblasts under two- and three-dimensional culture conditions. Tissue Eng. 12, 257, 2006.

37. Sun, T., Jackson, S., Haycock, J.W., and MacNeil, S. Culture of skin cells in $3 \mathrm{D}$ rather than $2 \mathrm{D}$ improves their ability to survive exposure to cytotoxic agents. J. Biotechnol. 122, 372, 2006.

38. Stegemann, J.P. and Nerem, R.M. Altered response of vascular smooth muscle cells to exogenous biochemical stimulation in two- and three-dimensional culture. Exp. Cell Res. 283, 146, 2003.

39. Cukierman, E., Pankov, R., Stevens, D.R., and Yamada, K.M. Taking cell-matrix adhesions to the third dimension. Science 294, 1708, 2001.

40. Chen, P., Marsilio, E., Goldstein, R.H., Yannas, I.V., and Spector, M. Formation of lung alveolar-like structures in collagen-glycosaminoglycan scaffolds in vitro. Tissue Eng. 11, 1436, 2005.

41. Tozer, S. and Duprez, D. Tendon and ligament: development, repair and disease. Birth Defects Res. C. Embryo. Today 75, 226, 2005.

42. Geutjes, P.J., Daamen, W.F., Buma, P., Feitz, W.F., Faraj, K.A., and Van Kuppevelt, T.H. From molecules to matrix: construction and evaluation of molecularly-defined bioscaffolds. Adv. Exp. Med. Biol. 585, 279, 2006.

Address reprint requests to:

Willeke F. Daamen, Ph.D.

Department of Biochemistry 280

Nijmegen Centre for Molecular Life Sciences Radboud University Nijmegen Medical Centre

P.O. Box 9101

$6500 \mathrm{HB}$ Nijmegen

The Netherlands

E-mail: w.daamen@ncmls.ru.nl 


\section{This article has been cited by:}

1. Weilun Sun, Dorien M. Tiemessen, Marije Sloff, Rianne J. Lammers, Eric L.W. de Mulder, Jöns Hilborn, Bhuvanesh Gupta, Wout F.J. Feitz, Willeke F. Daamen, Toin H. van Kuppevelt, Paul J. Geutjes, Egbert Oosterwijk . Improving the Cell Distribution in Collagen-Coated Poly-Caprolactone Knittings. Tissue Engineering Part C: Methods, ahead of print. [Abstract] [Full Text HTML] [Full Text PDF] [Full Text PDF with Links]

2. Katrien M. Brouwer, Willeke F. Daamen, Daphne Reijnen, Ruud H. Verstegen, Gerwen Lammers, Theo G. Hafmans, Ronnie G. Wismans, Toin H. Kuppevelt, René M. Wijnen. 2012. Repair of surgically created diaphragmatic defect in rat with use of a crosslinked porous collagen scaffold. Journal of Tissue Engineering and Regenerative Medicine n/a-n/a. [CrossRef]

3. Miss Weilun Sun, Mrs. Dorien Tiemessen, Marije Sloff, Miss Rianne J. Lammers, Mr. Eric L.W. de Mulder, Prof. Jöns Hilborn, Bhuvnesh Bhuvnesh Gupta, Prof. Wout F. Feitz, Dr. Willeke F. Daamen, Dr. Toin H. van Kuppevelt, Dr. Paul Geutjes, Dr. Egbert Oosterwijk . Improving the cell distribution in collagen coated PCL knittings. Tissue Engineering Part C: Methods 0:ja. . [Abstract] [Full Text PDF] [Full Text PDF with Links]

4. Willeke Daamen, Kaeuis Faraj, Martin Koens, Gerwen Lammers, Katrien Brouwer, Peter Uijtdewilligen, Suzan Nillesen, Luc Roelofs, Jody Nuininga, Paul Geutjes, Wouter Feitz, Toin van KuppeveltExtracellular Matrix-Based Scaffolds from Scratch 385-398. [CrossRef]

5. Ting-Wu Qin, Qingshan Chen, Yu-Long Sun, Scott P. Steinmann, Peter C. Amadio, Kai-Nan An, Chunfeng Zhao. 2012. Mechanical characteristics of native tendon slices for tissue engineering scaffold. Journal of Biomedical Materials Research Part B: Applied Biomaterials n/a-n/a. [CrossRef]

6. Cancan Xu, Wei Lu, Shaoquan Bian, Jie Liang, Yujiang Fan, Xingdong Zhang. 2012. Porous Collagen Scaffold Reinforced with Surfaced Activated PLLA Nanoparticles. The Scientific World Journal 2012, 1-10. [CrossRef]

7. N. Davidenko, T. Gibb, C. Schuster, S.M. Best, J.J. Campbell, C.J. Watson, R.E. Cameron. 2011. Biomimetic collagen scaffolds with anisotropic pore architecture. Acta Biomaterialia . [CrossRef]

8. Gerwen Lammers, Els M. van de Westerlo, Elly M. Versteeg, Toin H. van Kuppevelt, Willeke F. Daamen . 2011. A Comparison of Seven Methods to Analyze Heparin in Biomaterials: Quantification, Location, and Anticoagulant Activity. Tissue Engineering Part C: Methods 17:6, 669-676. [Abstract] [Full Text HTML] [Full Text PDF] [Full Text PDF with Links]

9. Beste Kinikoglu, José Carlos Rodríguez-Cabello, Odile Damour, Vasif Hasirci. 2011. A smart bilayer scaffold of elastin-like recombinamer and collagen for soft tissue engineering. Journal of Materials Science: Materials in Medicine 22:6, 1541-1554. [CrossRef]

10. Nima Saeidi, Edward A. Sander, Ramin Zareian, Jeffrey W. Ruberti. 2011. Production of highly aligned collagen lamellae by combining shear force and thin film confinement. Acta Biomaterialia 7:6, 2437-2447. [CrossRef]

11. Katrien M. Brouwer, Paul van Rensch, Veroniek E.M. Harbers, Paul J. Geutjes, Martin J.W. Koens, René M.H. Wijnen, Willeke F. Daamen, Toin H. van Kuppevelt. 2011. Evaluation of methods for the construction of collagenous scaffolds with a radial pore structure for tissue engineering. Journal of Tissue Engineering and Regenerative Medicine 5:6, 501-504. [CrossRef]

12. Martin J.W. Koens, Paul J. Geutjes, Kaeuis A. Faraj, Jöns Hilborn, Willeke F. Daamen , Toin H. van Kuppevelt . 2011. Organ-Specific Tubular and Collagen-Based Composite Scaffolds. Tissue Engineering Part C: Methods 17:3, 327-335. [Abstract] [Full Text HTML] [Full Text PDF] [Full Text PDF with Links]

13. S.T.M. Nillesen, G. Lammers, R.G. Wismans, M.M. Ulrich, E. Middelkoop, P.H. Spauwen, K.A. Faraj, J. Schalkwijk, W.F. Daamen, T.H. van Kuppevelt. 2011. Design and in vivo evaluation of a molecularly defined acellular skin construct: Reduction of early contraction and increase in early blood vessel formation. Acta Biomaterialia 7:3, 1063-1071. [CrossRef]

14. Matthew G. Haugh, Ciara M. Murphy, Fergal J. O'Brien . 2010. Novel Freeze-Drying Methods to Produce a Range of Collagen-Glycosaminoglycan Scaffolds with Tailored Mean Pore Sizes. Tissue Engineering Part C: Methods 16:5, 887-894. [Abstract] [Full Text HTML] [Full Text PDF] [Full Text PDF with Links]

15. Young-Gwang Ko, Sarah Grice, Naoki Kawazoe, Tetsuya Tateishi, Guoping Chen. 2010. Preparation of CollagenGlycosaminoglycan Sponges with Open Surface Porous Structures Using Ice Particulate Template Method. Macromolecular Bioscience 10:8, 860-871. [CrossRef]

16. Xiaoming He, Hongxu Lu, Naoki Kawazoe, Tetsuya Tateishi, Guoping Chen . 2010. A Novel Cylinder-Type Poly(LLactic Acid)-Collagen Hybrid Sponge for Cartilage Tissue Engineering. Tissue Engineering Part C: Methods 16:3, 329-338. [Abstract] [Full Text HTML] [Full Text PDF] [Full Text PDF with Links]

17. Naoki Kawazoe, Chieko Inoue, Tetsuya Tateishi, Guoping Chen. 2010. A cell leakproof PLGA-collagen hybrid scaffold for cartilage tissue engineering. Biotechnology Progress 26:3, 819-826. [CrossRef] 
18. S.C.G. Leeuwenburgh, I.D. Ana, J.A. Jansen. 2010. Sodium citrate as an effective dispersant for the synthesis of inorganicorganic composites with a nanodispersed mineral phase. Acta Biomaterialia 6:3, 836-844. [CrossRef]

19. Paul J. Geutjes, Kaeuis A. Faraj, Willeke F. Daamen, Toin H. van Kuppevelt. 2010. Preparation of differently sized injectable collagen micro-scaffolds. Journal of Tissue Engineering and Regenerative Medicine n/a-n/a. [CrossRef]

20. Young-Gwang Ko, Naoki Kawazoe, Tetsuya Tateishi, Guoping Chen. 2010. Preparation of chitosan scaffolds with a hierarchical porous structure. Journal of Biomedical Materials Research Part B: Applied Biomaterials 9999B, NA-NA. [CrossRef]

21. Nima Saeidi, Edward A. Sander, Jeffrey W. Ruberti. 2009. Dynamic shear-influenced collagen self-assembly. Biomaterials 30:34, 6581-6592. [CrossRef]

22. G. Lammers, G.S. Tjabringa, J. Schalkwijk, W.F. Daamen, T.H. van Kuppevelt. 2009. A molecularly defined array based on native fibrillar collagen for the assessment of skin tissue engineering biomaterials. Biomaterials 30:31, 6213-6220. [CrossRef]

23. Kaeuis A. Faraj, Vincent M.J.I. Cuijpers, Ronnie G. Wismans , X. Frank Walboomers, John A. Jansen , Toin H. van Kuppevelt, Willeke F. Daamen . 2009. Micro-Computed Tomographical Imaging of Soft Biological Materials Using Contrast Techniques. Tissue Engineering Part C: Methods 15:3, 493-499. [Abstract] [Full Text HTML] [Full Text PDF] [Full Text PDF with Links] [Supplemental material]

24. Kaoru Aoki, Yuki Usui, Nobuyo Narita, Nobuhide Ogiwara, Norio Iashigaki, Koichi Nakamura, Hiroyuki Kato, Kenji Sano, Naoko Ogiwara, Kiyokazu Kametani, Chan Kim, Seiichi Taruta, Yoong Ahm Kim, Morinobu Endo, Naoto Saito. 2009. A Thin Carbon-Fiber Web as a Scaffold for Bone-Tissue Regeneration. Small 5:13, 1540-1546. [CrossRef]

25. Allison J. Beattie, Thomas W. Gilbert, Juan Pablo Guyot, Adolph J. Yates, Stephen F. Badylak . 2009. Chemoattraction of Progenitor Cells by Remodeling Extracellular Matrix Scaffolds. Tissue Engineering Part A 15:5, 1119-1125. [Abstract] [Full Text HTML] [Full Text PDF] [Full Text PDF with Links]

26. Adolfo A. Leirner, Virgílio Tattini, Ronaldo N.M. Pitombo. 2009. Prospects in Lyophilization of Bovine Pericardium. Artificial Organs 33:3, 221-229. [CrossRef]

27. W. A. FARHAT, P. J. GEUTJESArtificial biomaterials for urological tissue engineering 243-254. [CrossRef]

28. Jian-Zheng Wang, Xiao-Bo Huang, Jing Xiao, Wei-Ting Yu, Wei Wang, Wei-Yang Xie, Ying Zhang, Xiao-Jun Ma. 2009. Hydro-spinning: A novel technology for making alginate/chitosan fibrous scaffold. Journal of Biomedical Materials Research Part A 9999A, NA-NA. [CrossRef]

29. Jeffrey W. Ruberti, James D. Zieske. 2008. Prelude to corneal tissue engineering - Gaining control of collagen organization. Progress in Retinal and Eye Research 27:5, 549-577. [CrossRef]

30. G. Chen, N. Kawazoe, T. TateishiCollagen-based scaffolds for tissue engineering 396-415. [CrossRef] 